\title{
CONSIDERAÇÕES SOBRE O ROMANCE HISTÓRICO
}

Marilene Weinhardt*

uando os historiadores, na tentativa de dar conta dos processos históricos, buscam os recursos da abordagem literária, referem-se à literatura como ficção ou como narrativa, em geral usando os dois termos como equivalentes, mas não aludem especificamente à fiç̧ão de caráter histórico, campo em que o problema já existia muito antes da atual tendência de aproximação dos estudos históricos e literários. Talvez justamente aí esse diálogo tenha mais a oferecer à literatura. Em vista das novas abordagens da história, a mais corriqueira pergunta diante do romance histórico - esta é a verdade histórica ou não? - perdeu sua razão de ser, uma vez que todas as formas de resgate do passado são permeadas pela consciência de que a construção verbal não é o fato e não é ingênua. Mas, ainda que o referente externo possa não ser relevante para os procedimentos de análise, dificilmente o leitor o ignora ou despreza.

M. Bakhtin, além de apontar a variedade da organização do plurilingüismo no romance e os modos de que este dispõe para incorporar as diversas

* Universidade Federal do Paraná 
linguagens, ${ }^{1}$ estabelece uma distinção entre epopéia e romance que não se limita aos aspectos históricos e nem aos formais, mas mostra que cada gênero (entendido aqui como "epos" e como "romance", termos que dão título ao capítulo) ${ }^{2}$ comporta uma concepção de tempo, o que por sua vez é a expressão de mundos distintos, presididos por estruturas sociais diversas, por diferentes conceitos e funçōes de arte.

O epos já não tem lugar no presente, é um gênero fechado e encerrado como o mundo que representou, enquanto o romance é o único a se encontrar em processo de construção, capaz de dar conta da multiplicidade do presente justamente pelo seu caráter acanônico. O tempo representado na epopéia é o 'passado absoluto', fechado e inquestionável, a ser reverenciado sem crítica, com uma hierarquia estratificada e heróis que sumarizam em si o passado heróico nacional, heróis sem fissura entre o aspecto externo e interno, direito e avesso perfeitamente idênticos, ação e modo de ser sem conflitos.

A inconsciência da epopéia quanto à relatividade do passado pode ser a chave para se estabelecer a diferença e, conseqüentemente, o traço fundamental do romance, sobretudo quando acrescido do adjetivo histórico. A matéria do romance é o passado histórico, ainda vivo, sujeito a revisões, inconfundível com o passado mítico, cristalizado, imutável. O romance não comporta heróis, no sentido clássico, mas seres humanos, igualmente capazes de atos heróicos determinados por motivos vis e de açōes condenáveis movidas por sentimentos nobres.

Assim, da perspectiva bakhtiniana, a denominação romance histórico não é determinada por qualquer traço interno, mas é um dado externo, peculiaridade sem relevância para a realização estética. Entretanto, é ainda lição de Bakhtin que o romance pode, em vista de sua capacidade de incorporar qualquer outro discurso, eventualmente valer-se inclusive de procedimentos épicos.

Qualquer comentário de ordem teórica sobre o romance histórico não pode ignorar o trabalho pioneiro e em certo sentido ainda único de George Lukàcs, O Romance Histórico ${ }^{3}$, texto datado de 1937 , sem tradução para o português, apesar de seu caráter de referência obrigatória.

O próprio Lukács, no prefácio escrito para a ediçāo inglesa (1960), reproduzido na edição francesa, da qual me sirvo, diz da necessidade de atualizar certos aspectos históricos mas, face à impossibilidade de fazê-lo, entre

1 BAKHTIN, Mithail. O discurso no romance. In Questōes de literatura e de estética. A tooria do romance. Trad. Aurora Fomoni Bemardini el al. 2.ed. São Paulo: Unesp; Hucitec, 1990. p.71-210.

2 . Epos e romance. In Questöes...p.397-428.

3 LE ROMAN historique. Trad. Robert Sailley. [s/ed.] Paris : Payol, 1972. 
publicar apesar das restriçōes que julgava que o livro já merecia ou deixar de publicá-lo, opta pela primeira alternativa, mesmo porque, como acentua, seus objetivos são de natureza teórica, "un examen théorique de l'action réciproque entre l'esprit historique et cette grande littérature qui décrit la totalité de l'histoire, et ceci seulement à propos de la littérature bourgeoise... ${ }^{4}$, perspectiva sob a qual considerava que seu trabalho continuava válido. Ainda que $o$ ensaio seja também de caráter histórico, não tem a pretensão de ser historicamente completo, já declarava o "Avant-propos" de 1937.

Lukács situa o nascimento do romance histórico no início do século XIX, com Walter Scott, coincidindo com a queda de Napoleão. Aos textos antecendentes que situam a ação em épocas pretéritas falta justamente o que o crítico marxista considera a condição fundamental para o histórico: a especificidade histórica do tempo da ação condicionando o modo de ser e de agir das personagens. As grandes transformações que marcaram os povos europeus entre 1789 e 1814 reforçou-lhes a consciência histórica. A guerra, não mais restrita aos militares, atingindo os cidadãos, produz um alargamento de horizonte e a difusão do sentimento de nacionalidade entre a massa. Os heróis de Walter Scott não são as grandes figuras históricas. Ao romance histórico não interessa repetir o relato dos grandes acontecimentos, mas ressuscitar poeticamente os seres humanos que viveram essa experiência. Ele deve fazer com que o leitor apreenda as razões sociais e humanas que fizeram com que os homens daquele tempo e daquele espaço pensassem, sentissem e agissem da forma como o fizeram. Trata-se de uma norma da figuração literária, aparentemente paradoxal, que se alcance esta apreensão focalizando os detalhes do quotidiano que parecem insignificantes. Os grandes dramas e as figuras históricas centrais são próprios para a epopéia. O mundo do romance é o da esfera popular. Esta, tensionada pela revolução, pode revelar suas forças, surgindo naturalmente os heróis que para a história são incógnitos.

Lukács acentua que o romance histórico não é um gênero ou subgênero, funcionalmente distinto do romance. Sua especificidade, que $\varepsilon$ a de figurar a grandeza humana na história passada, deve resolver-se nas características gerais da forma romanesca, o que inclui também a possibilidade de apresentar as figuras históricas em momentos historicamente decisivos. A arte do romancista consiste em colocá-las na intriga de modo que essa situação decorra da lógica interna das açōes.

4 "um exame teórico da açāo recíprocia entre o espirito histórico e essa grande literatura que descreve a totalidade da história, e isso somente a propósito da literatura burguesa..." Ibidem p. 12 
Lukács critica o escritor que escreve romances históricos por repudiar o presente, por fuga, por desejo de evasão, o que lhe parece produzir um empobrecimento do mundo figurado. $O$ bom romance histórico resulta da compreensão do relacionamento entre o passado histórico e o tempo presente.

Os textos comentados a seguir não têm a pretensāo de apresentar levantamento exaustivo do percurso e do estágio atual dos estudos sobre o romance histórico. Apenas ilustram alguns pontos relevantes deste trajeto.

Em 1972, La Nouvelle Revue Française dedica um número ao romance histórico. Pela organização, pela escolha de colaboradores e pelo conjunto dos artigos, ainda que não se possa afirmar que houvesse uma clara atenção à confluência que começava então a se delinear, é possivel perceber que se entrevia a possibilidade do diálogo que a teoria da história buscava. $O$ ensaio introdutório, longo, de Claude Mettra, isolado das sessões, focaliza o trabalho do romancista que enfrenta a tarefa de escrever romances históricos, destacando suas relações com a história, com o passado. A conclusão é de que talvez o passado histórico nada mais tenha a nos dizer, mas a ficção histórica permite ao escritor fugir das armadilhas e das imposturas do eu: "Ainsi, par un étrange renversement des rôles, la littérature historique, qui semblait se condamner à coller à la réalité la plus franche, la plus objective puisqu'elle se confondait avec des traits, des oeuvres, des hommes concrets, apparaît désormais comme un dérisoire et magnifique théâtre de l'illusion. " 5

Poderá ser um bom exercício verificar se este raciocínio se aplica à literatura brasileira. Em que medida a história serviria aos escritores brasileiros apenas para dar a palavra a outro, opondo-se ao exclusivismo do eu, centro das demais formas romanescas?

A Reırue d'Histoire Littéraire de la France dedica um número de 1975 ao romance histórico, reservando a primeira seção, com três artigos, à teoria, enquanto as demais seçōes são dedicadas a uma abordagem cronológica. ${ }^{6}$

O número publicado na primavera de 1983 dos Cahiers de Recherche de S.T.D. é intitulado Roman - Histoire. ${ }^{7}$ A posição, explicitada desde o título, já não é de caracterizar o romance histórico, mas de caracterizar as relações entre o romance e a história. As preocupações giram em torno dos processos de resgate do passado e suas relações com o presente, das razões porque esta ou aquela época é privilegiada, das fronteiras entre história e ficção, do papel

5 "Assim, por uma estranha troca de papéis, a literatura histórica, que parecia condenada a se colar à realidade mais franca. mais objetiva. višo que sla se confundia com traços, obras e homens coniretos, apariè entretanto como um irrisório e magnifico teatro da ilusão" Le romancier hors les murs. La Nowelle rense française. Paris, n.238, Oct. 1972. p.7.

6 REVUE d'histoire littéraire de la France. Paris, mars-juin 1975.

7 CAHIERS de recherche de S.T.D. Roman - histoire. Paris, n.12, printemps 1983. 
da memória e da história das mentalidades, das funções e do lugar do messianismo, dos modos de representação da temporalidade. É perceptível como o eixo de atenção é outro e como a metodologia mudou. A partir da análise de textos ficcionais contemporâneos, busca-se refletir sobre a ordem das relações entre a literatura e a história.

Os trabalhos apresentados num simpósio sobre o romance histórico na América Latina, realizado na Universidade Tulane em novembro de 1985 , foram reunidos sob o título The Historical novel in Latin America. ${ }^{8} 0$ conjunto, além de ser expressivo quanto ao número de romances históricos produzidos na América Latina de fala espanhola, mostra-se totalmente integrado à atual confluência dos estudos históricos e literários. Resultados de pesquisas em sua maioria realizadas em universidades norte-americanas, há um único estudo sobre escritor brasileiro (do inglês John Gledson sobre Machado de Assis). $\mathrm{O}$ espaço geográfico e social do Brasil é lembrado em função de $A$ Guerra do Fim do Mundo, do peruano Mario Vargas Llosa, tema de dois artigos. Escritores brasileiros contemporâneos são citados na introdução (Graciliano Ramos, Jorge Amado e Érico Veríssimo), assinada pelo editor, mas nenhum é abordado com mais vagar.

Outra contribuição para o estudo das relações entre a literatura e a história vem do outro lado do Atlântico. O periódico Dedalus, Revista Portuguesa de Literatura Comparada, ${ }^{9}$ dedica um número ao tema "Facto e ficção na literatura e na teoria literária", publicando as atas do V Colóquio do Comité de Teoria Literária da Associação Internacional de Literatura Comparada, realizado na Universidade da Madeira, em junho de 1992. A maioria dos textos, perfeitamente enfronhados no diálogo entre literatura e história, é de caráter teórico, mas alguns contemplam obras específicas, sobretudo aqueles escritos por professores de universidades portuguesas. Nenhum escritor brasileiro é estudado.

$O$ isolamento da literatura brasileira se dá em todos os quadrantes. Estudos sobre a América Latina realizados nos Estados Unidos praticamente só consideram a produção em espanhol. Em outro continente, aqueles que não têm a barreira da língua também nos ignoram. Entretanto, temos uma produção que, em termos comparativos, se não for considerável, certamente não é desprezível. Entre tantas outras razões para o atual alijamento do Brasil do diálogo cultural internacional, especificamente quanto à desatenção à nossa fiç̧ão de caráter histórico, é o caso de se examinar se a falta de interesse e/ou

8 Daniel BALDERSTON é o onganizador e faz a introdução, aparecendo no volume como editor. Garthersburg : Ediciones Hispanoamérica, 1986.

9 DEDALUS. Lisboa : Cosmos, n.2, dez. 1992. 
reconhecimento por parte de estrangeiros não cabe, em certa medida, à própria crítica nacional, que pouco estuda, ou pelo menos não dá o devido destaque à uma fatia ponderável da produção ficcional contemporânea.

No Brasil, ainda que o romance histórico especificamente não ocupe muitas atenções, o diálogo entre os estudiosos da ficção e da história intensificou-se a partir do final dos anos oitenta, em seminários e simpósios que originam publicações que tendem a ampliar o debate. Entre esses eventos, merecem destaque pelo temário, pela amplitude e pelo nível de trabalhos apresentados, o "Colóquio Narrativa: Ficção e História", realizado no Rio de Janeiro em 1987, organizado por Dirce Cortes Riedel ${ }^{10}$ e o "Encontro Internacional sobre Literatura e História na América Latina", em 1991, patrocinado pelo Centro Angel Rama (SP) e organizado por Lígia Chiappini e Flávio Wolf Aguiar. ${ }^{11}$

Entre as publicações citadas a título de exemplificação sobre como o assunto recebe tratamento e atenção variados, vale a pena lembrar uma obra francesa recente, de caráter paradidático. Gérard Vindt e Nicole Giraud organizam Les Grands Romans Historiques: l'Histoire à travers les Romans. ${ }^{12}$ $O$ subtítulo é significativo do modo de se entender a função da literatura e quanto às possibilidades de uma tendência teórica tranformar-se em modismo, com sérias probabilidades de leituras apressadas não desfazerem condicionamentos prévios e trairem a essência da teoria. Além desse desvirtuamento, o sumário denuncia fusão, se não confusão de critérios. Para a Europa tradicionalmente reconhecida como culta, o critério é cronológico, a partir de duas concepções:fatos históricos marcantes para a época mais recente, e grandes períodos, definidos pela Antropologia, para as épocas mais longínquas. A apresentação da literatura dos "bárbaros", isto é, os não habitantes da Europa branca e civilizada, obedece critério geográfico, resquício de uma visão exótica. Merece ser notada ainda a acepção pouco ortodoxa de romance histórico. $O$ último capítulo é sobre ficção cientifica, ou melhor, sobre romances ambientados no mundo do futuro. É uma concepção tão ampla que muito poucos romances não seriam incluídos entre os históricos. Em que pese a falta de rigor nos critérios, tratando-se de obra destinada a guia do grande público, pode ser vista como significativa de quão pouco importa para o leitor qualificar o romance como histórico ou não. Vale lembrar que há também na produção

10 Comunicações e debates foram publicados no volume Narrativa: fição e história. Rio de Janeiro : Imago, 1988

11 Atas publicadas sob o título Literatura e história na América Latina. São Paulo : Editora da Universidade de São Paulo, 1993.

12 VINDT, Gérard \& GIRAUD, Nicole. Les grands romans historiques, l'histoire à travers les romans, Paris : Bordas, 1991. 
ficcional contemporânea uma vertente de grande apelo popular, com nomes como Marion Zimmer Bradley e J. Plaidy.

A noção de que a ficção histórica pode ser usada no ensino da história é corrente não só entre os leigos, mas entre os historiadores e mesmo entre os estudiosos da literatura. Temístocles Linhares, analisando romances históricos brasileiros, ainda que não chegue a atribuir-lhes uma função didática, deixa claro que o texto ficcional lhe parece mais degustável e, eventualmente, mais completo do que o histórico. O papel da imaginação fica limitado a suprir as lacunas documentais, além de avivar o texto, mas cabe à história, uma história que contém a verdade, precedência sobre qualquer outro valor. ${ }^{13}$ Jacques Le Goff acredita que a atividade do historiador pode também ser exercida convenientemente por amadores, e até vê nesse trabalho de diletantes uma utilidade, a vulgarização necessária, tarefa para a qual os historiadores profissionais em geral não se prestam. $O$ passo seguinte é propor "um setor literário da história-ficção na qual, respeitando os dados de base da história - costumes, instituições, mentalidades - fosse possível recriá- la, jogando com o acaso e com o événemetiel? Teria então o duplo prazer da surpresa e do respeito pelo que há de mais importante em história. ${ }^{14}$ A proposta não está muito distante do ideal neoclássico docere cum delectare. Os reflexos do Século das Luzes ainda piscam. Pode-se também concluir que, nessa concepção historiocêntrica, concebe-se a fiç̧ão como um método pedagógico auxiliar no ensino da história. $\mathrm{O}$ uso do cachimbo entorta a boca, mesmo dos mais lúcidos.

Desde que a narrativa ficcional alcançou foros de cidadania estética, o romance histórico alterna períodos de brilho com períodos de obscuridade. $\mathrm{Na}$ literatura brasileira não é diferente, mas a história da literatura não se deteve com vagar e rigor no percurso do romance histórico entre nós, ainda que a produção não seja desprezivel quantitavamente e às vezes qualitativamente. $\dot{E}$ comum negar-se-lhe a condição de forma menor, atitude compreensivel em vista da recorrência de opiniões como as comentadas acima, mas raramente se aprofunda a questão, mostrando objetivamente o caráter e a função do romance histórico. Nos estudos sobre autores que os praticam, o assunto é forçosamente abordado, mas raramente de modo a colocá-lo em destaque. Há artigos e ensaios sobre romances históricos específicos, mas nenhum estudo sistemático de monta. O trabalho mais abrangente ficou praticamente na intenção. $O$

13 Histónia crítica do romance brasileiro. 1728-1981. Belo Horizonte : Itatiaia; Sāo Paulo : Editora da Universidade de Sāo Paulo, 1987. p.638.

14 História e memória. Trad. Bernardo Leitão et al. Campinas : Editora da UNICAMP, 1990. p.50-51. 
Romance Histórico na Literatura Brasileira, de José Antônio Pereira Ribeiro, ${ }^{15}$ além de uma entusiástica apresentaçāo da obra de Paulo Setúbal, seu objetivo fundamental, limita-se a registrar a existência de algumas obras que de outra forma poderiam cair no esquecimento, pouco expressivas esteticamente mas com um lugar na história do romance histórico no Brasil. É virtude que se lhe deve creditar.

Nesta altura do estudo das relações entre história e ficção, talvez já não haja lugar para a história do romance histórico, uma vez que até a denominação agora merece ser questionada. Os aspectos que caberiam a tal abordagem vêm sendo trabalhados de modo mais amplo nos jogos de semelhanças e diferenças entre os dois discursos. Desde Lukács, ficou claro que o qualificativo indica assunto, mas não condiciona nenhum procedimento específico, princípio que se confirma em Bakhtin. No entanto, não se pode negar que, na literatura contemporânea, há uma linhagem significativa de romances voltados para o passado, ainda que as expressōes mais criativas já não se conformem aos padrões de excelência lukacsianos. $O$ romance histórico contemporâneo não se confunde nem com o de Walter Scott, nem com o de Flaubert, respectivamente modelo e antimodelo para Lukács. Flávio Loureiro Chaves, em ensaio breve mas preciso em que comprova que o "romance brasileiro definiu-se (...) como romance histórico no momento decisivo de sua estruturação", ${ }^{16}$ comentando como Machado de Assis realiza, em Esaú e Jacó, a metáfora da vida política brasileira, observa:

Daí advém, para a modernidade, uma lição importante, que diz respeito à própria definição de romance histórico. Por si só, não é histórica aquela literatura que compete com a crônica pura e simples dos fatos ou inclui em sua matéria eventos e figuras decalcadas diretamente sobre a existência real. Entretanto, poderá sê-lo (e com maior força de conviç̧ão) aquela que, embora totalmente fictícia, assume como preocupação central a História e a expressão de uma visão histórica. ${ }^{17}$

15 Sāo Paulo : Secretaria da Cultura, Ciência e Tecnologia, Conselho Estadual de Cultura, 1976.

16 História e ficçāo no romarxe brasileiro. In: . História e literanara. Pono Alegre: Editora da Universidade/UFRGS: MEC/SESu?PROED, 1988. p.19.

17 lbidem p.22 
Noé Jitrik ${ }^{18}$ observa que, em vista da produção dos últimos trinta anos, o antigo conceito de romance histórico alterou-se, dando lugar a mani festaçōes que têm relações mais estreitas com a história da literatura e da escrita do que com a história propriamente dita. Jitrik destaca alguns comportamentos que classifica como intraliterários: a proliferação das possibilidades narrativas; a penetração da linguagem da poesia na narrativa; a derrocada dos conceitos tradicionais de verossimilhança e de linearidade. Estes últimos eram considerados a viga mestra de qualquer romance e tinham implicações especiais no romance histórico, que parecia fadado a não resistir na ausência dos dois traços. No entanto, acaba encontrando o caminho do realismo mágico, da descontinuidade e da fragmentação.

A teorização de Linda Hutcheon não está distante das observações de Noé Jitrik. Na sua proposta de uma poética do pós-modernismo, ela enfrenta, sem o subterfúgio das generalizações, a fiç̧ão contemporânea que resgata $o$ passado sem se confundir com a ficção histórica do século XIX:

este livro (...) vai privilegiar o gênero romance, especialmente uma de suas formas, que quero chamar de 'metaficção historiográfica'. Com este termo refiro-me àqueles romances famosos e populares que, ao mesmo tempo são intensamente auto-reflexivos e mesmo assim, de mancira paradoxal, também se apropriam de acontecimentos e personagens históricos (...). A metaficção historiográfica (...) sempre atua dentro das convenções a fim de subvertê-las. Ela não é apenas metaficcional; nem é apenas mais uma versão do romance histórico ou do romance não-ficcional. ${ }^{19}$

O capítulo dedicado à teorização da metaficção historiográfica, anunciado pelo sugestivo subtítulo "O Passatempo do tempo passado" (com aspas), fartamente exemplificado, chama a atenção para a importância da teorização de Lukács, recomendando aos teóricos que o leiam mais e melhor, mas mostra que os critérios do crítico marxista não dão conta de parte da produção de romances contemporâneos, aparentados com o romance histórico, mas que já não se confundem com ele. Citando Umberto Eco, que no Pósescrito a $O$ Nome da Rosa indica três modos de narrar o passado - a fábula, a estória heróica

18 De la historia a la escritura: predominios, diimetrías, acuerdos en la novela histórica latinoamericana. In: BALDERSTON, Daniel (ed.) The Historical novel in Latin America . p.13.

19 Pótica do pós-modermismo: história, teoria e ficçāo. Trad. Ricando Cruz. Rio de Janeiro : Imago, 1991. p.21-22. 
e o romance histórico - Linda Hutcheon propōe que narrativas como $O$ Nome da Rosa, que o próprio Eco classificou no terceiro modo, sejam vistas como uma quarta maneira de narrar, batizada como metaficção historiográfica, que já não se confunde com a fiç̧ão histórica por comportar uma aguda autoconsciência de seu processo de constituição. São obras que "não só identificam no passado causas para o que veio depois, mas também investigam o processo pelo qual, lentamente, essas causas começam a produzir seus efeitos". ${ }^{20}$

Sem entrar na discussão sobre o pós-modernismo e nem no seu mérito, o que desviaria o eixo do assunto discutido, a abordagem de determinados romances sob a perspectiva proposta por Linda Hutcheon será sem dúvida um modo de reconhecê-los na diferença. Um novo fenômeno exige ser nomeado de modo também novo. A falta de outro nome, aceitemos metafiç̧ão historiográfica, apesar de seu peso sonoro, gráfico e filológico.

\section{RESUMO}

Este texto apresenta etapa de uma reflexāo a respeito da ficção histórica contemporânea, face ao legado de romances históricos do século XIX e à atual aproximação dos estudos históricos e literários.

Palavras-chave: Fiç̧ão contemporånea, Romance histórico, Romance e História

\section{RÉSUMÉ}

Ce texte présente une étape d'une réflexion sur la fiction historique contemporaine, devant l'héritage laissé par le roman historique du XIXème siècle et l'approche actuelle des études historiques et littéraires.

20 ECO, Humberto. Apud HUTCHEON, Linda. Pó́tica... p.150 ( Na traduçāo brasileira, a terminologia usada é "romance", "romance de capa e espada" e "romance histórico". Trad. Letizia Zini Antunes e Álvaro Lorencicni. Sāo Paulo: Nowa Fronteira, 1985. p.62) 


\section{REFERÊNCIAS BIBLIOGRÁFICAS}

BAKHTIN, Mikhail. Questōes de literatura e de estética. A teoria do romance. Trad. Aurora Fornoni Bernardini el al. 2.ed. São Paulo : Unesp; Hucitec, 1990.

BALDERSTON, Daniel (ed.) The historical novel in Latin America. Garthersburg : Ediciones Hispanoamérica, 1986.

CAHIERS de recherche de S. T. D. Roman - Histoire. Paris, n. 12, printemps 1983.

CHAVES, Flàvio Loureiro. História e literatura. Porto Alegre : Editora da Universidade/ UFRGS; MEC/SESU/PROED, 1988.

CHIAPPINI, Lígia \& AGUIAR, Flávio Wolf de (Orgs) Literatura e história na América Latina. São Paulo : Editora da Universidade de São Paulo, 1993.

DEDALUS. Lisboa : Cosmos, n. 2, dez. 1992.

ECO, Umberto. Pós-escrito a O Nome da rosa. Trad. Letizia Nunes Zini Antunes e Álvaro Lorencini. São Paulo : Nova Fronteira, 1985.

GUIRAUD, Nicole ; VINDT, Gérard. Les grands romans historiques: l'histoire à travers les romans. Paris : Bordas, 1991.

HUTCHEON, Linda. Poética do pós-modernismo: história, teoria e ficção. Trad. Ricardo Cruz. Rio de Janeiro : Imago, 1991.

LE GOFF, Jacques. História e memória. Trad. Bernardo Leitão et al. Campinas : Editora da UNICAMP, 1990.

LINHARES, Teméstocles. História crítica do romance brasileiro. 1728-1981. Belo Horizonte : Itatiaia; São Paulo : Editora da Universidade de São Paulo, 1987.

LUKÁCS, George. Le roman historique. Trad. Robert Sailley. [s/ed.] Paris : Payot, 1972.

LA NOUVELLE Revue Française. Paris, n. 238, oct. 1972.

REVUE d'Histoire Littéraire de la France. Paris, mars-juin, 1975.

RIBEIRO, José Antônio Pereira. O romance histórico na literatura brasileira. São Paulo : Secretaria da Cultura, Ciência e Tecnologia, Conselho Estadual de Cultura, 1976.

RIEDEL, Dirce Côrtes (org.) Narrativa: ficção e histótia. Rio de Janeiro : Imago, 1988. (Col. Tempo e Saber).

VINDT, Bérard \& GIRAUD, Nicole. Les grands romans historiques, L'histoire à travers les romans. Paris, Bordas, 1991. 